\title{
Inter-state Disparities in Socio-economic Development in North East Region of India
}

\author{
Amod Sharma ${ }^{1}$ \\ ${ }^{1}$ Department of Agricultural Economics, School of Agricultural Sciences \& Rural Development (SASRD), \\ Nagaland University, Nagaland, India \\ Correspondence: Amod Sharma, Department of Agricultural Economics, School of Agricultural Sciences \& \\ Rural Development (SASRD), Nagaland University, Medziphema, Dimapur, Nagaland 797 106, India. E-mail: \\ hodaec_sasrd@yahoo.co.in
}

Received: March 29, 2012 Accepted: May 14, 2012 Online Published: August 8, 2012

doi:10.5539/jas.v4n9p236

URL: http://dx.doi.org/10.5539/jas.v4n9p236

\begin{abstract}
The level of development of north east region has been estimated with the help of composite index based on optimum combination of socio-economic indicators. The state-wise data for the year 2006 on forty eight indicators were used for seven states (seven sisters) of the north east region of India. Fifteen indicators are directly concerned with agricultural development, nine indicators are directly concerned with livestock development, twelve indicators are concern with socio-economic development and the rest twelve indicators describe the level of development in infrastructural service sector. The level of development has been separately estimated for agricultural, livestock, infrastructure and overall socio-economic field. In case of socio-economic development, the Assam has been ranked first and Meghalaya is ranked last. Wide disparities were obtained in the level of development among different states. Positive Significant association is found between the Agriculture and Infrastructure fields. Literacy rate is also influencing the level of development in the positive direction. But the level of education, provision of health services, banking facilities, transport and communication system did not significantly influence the agricultural development. North eastern states require improvements of various dimensions in some of the indicators for enhancing the level of overall socio-economic development for unified balanced integration of curative, preventive and promotional health services.
\end{abstract}

Keywords: composite index, level of development, potential target, development indicators, inter-state disparities

\section{Introduction}

Development has been appropriately conceptualized as a process, which improves the quality of life. Government of India (GOI) since 1952 introduced phase manner development through 5 year plan (FYP), in FYP, more emphasis was given on infrastructure, communication, education, agriculture and livestock subsequently to uplift the socio-economic status in late eighties GOI introduced viz; Jawahar Rozgar Yojana (JRY), Swarn Jayanti Rozgar Yojana (SJRY), Samporn Gramin Rozgar Yojana (SGRY), Prime Minister's Grameen Rozgar Yojana (PMGRY), Employment Guarantee Scheme (EGS) etc; (Anon, 2008). The main objective is to enhance the quality of life of people as well as their social and economic well-being. The Green Revolution in agricultural sector and commendable progress in the industrial front have certainly increased the overall total production in India, but there is no indication that these achievements have been able to reduce substantially the regional inequality in the level of development. This study was made for evaluating the socio-economic development in the north east region.

In this paper study data for the years 1991-2006 in respect of 7 states had been critically analyzed and wide disparities in the level of development were found in different stages. It was, therefore, felt necessary to make a deeper analysis for socio-economic indicators for evaluating the imbalances of development in the north east region.

All India population the percentage of workers to total population was about 42.74 per cent. The population density of population is 120 per square kilometer and the annual growth of the population is the about 64.41 per cent. Agriculture is an important primary sector. It provides food to the growing population, row materials to the agro based industries and various other products to fulfill the basic needs. The region's economy is largely depends upon agricultural sector. Major food crops are rice, jowar, wheat, bajra, barely, maize and pulses. Important 
commercial crops grown in the state are sugarcane, cotton, jute, potato, coffee, tea, cardamom etc. The total forest area in this region about 11.68 per cent and the major forest products viz; teak, oak, bamboo, pulpwood and firewood.

\section{Data \& Methodology}

Development is a multidimensional continuous process. Its impact cannot be evaluated fully by any single indicator. Moreover, a number of indicators when analyzed individually do not provide an integrated and easily comprehensible picture of reality. Hence, there is a need for building up of a composite index of development based on various indicators combined in an optimum manner. For this study, the north eastern region haven been taken as the unit of analysis. 7 states of the north east region are included in the study. The data on following development indicators for the year (1991-2006) are utilized in the analysis. (Anon, 2006; 2010)

\subsection{Developmental Indicators}

Each state faces situational factors of development unique to it as well as common administrative and financial factors. Indicators which are common to all the states have been included in the analysis for evaluating the level of development. The composite indices of development have been calculated for different states by using the data and further computed on the following indicators these findings are in the line with Narain et. al, $2000 \& 2004$ and these data (2.1.1 to 2.1.4.) are secondary in nature of north eastern states (Anon, 2010).

\subsubsection{Agricultural Sector}

1) Productivity of total cereals,

2) Per capita cereals,

3) Productivity of pulses,

4) Productivity of oil seeds,

5) Productivity of sugarcane crop,

6) Productivity of cotton lint,

7) Productivity of tea plantation,

8) Productivity of rubber plantation,

9) Productivity of vegetable crops,

10) Productivity of fruits crop,

11) Consumption of fertilizers nutrients,

12) Consumption of pesticides,

13) Percentage to net cultivable area,

14) Gross crop area,

15) Farms and other facilities.

\subsubsection{Livestock sector}

1) Total milk production,

2) Per capita consumption of milk,

3) Total Production of eggs,

4) Per capita consumption of eggs,

5) Total meat production,

6) Per capita consumption of meat,

7) Number of veteneary and dispensary facilities,

8) Sericulture production and

9) Per capita fish production.

\subsubsection{Socio-economic}

1) Number of banks per lakh population,

2) Decadal growth rate of population, 
3) Population density,

4) Sex ratio,

5) Literacy rate (male),

6) Literacy rate (female),

7) Total literacy rate,

8) Birth rate,

9) Death rate,

10) Infant mortality rate,

11) Credit / Deposit ratio \&

12) Percentage of below poverty line to total population.

\subsubsection{Infrastructural Facilities}

1) Marketing co-operative facilities,

2) Percentage of electrified villages,

3) Percentage to per population Road length,

4) Number of Post office in sq. km.

5) Per capita number of motor vehicles,

6) Total numbers of Doordharsan Kendra / station,

7) Total numbers of All India Radio Station,

8) Per capita share in Ninth plan (1999-2002) (Anon, 2008),

9) Per capita share in Net Share to Domestic Product,

10) Setup with banks financing facilities,

11) Percentage to total number of industries and

12) Percentage of articians.

These indicators may not form an all inclusive list but these are the major interacting components of development in the region at different state level. Out of these indicators, fifteen indicators are depicting the progress of agricultural development, nine indicated are depicting the progress of livestock development, twelve are concerned with socio-economic and the rest twelve are concerned with the infrastructural facilities. (Narain et. al, 2000 \& 2002; Sharma et. al, 2008).

\subsection{Estimation of Composite Index of Level of Development}

Variables in respect of different indicators are taken from various population distributions and these are recorded in different levels of measurement. The values of these development indicators are not quite suitable for simple addition in combined analysis. For obtaining the composite index of development, the values of indicators are transformed as follows. These indicators also reflect some degree of variability.

Let $X_{i j}$ be the value of $j$ th indicator for ith unit, $i=1,2, \ldots, n$ and $j=1,2, \ldots, k$. $X_{i j}$ is transformed to $Z_{i j}$ as follows

$$
Z_{i j}=\left(X_{i j}-\bar{X}_{j}\right) / S_{j}
$$

Where $\bar{X}_{j}=$ mean of the jth indicator; $\mathrm{S}_{\mathrm{j}}=$ Standard Deviation (SD) of jth indicator

The best value of the transformed variables for different indicators applied during 1991-2006. The value obtained in the study is based on statistical analysis (with maximum value depending upon the direction of the impact of indicator on development) is identified and the squares of the deviations of the transformed variables from best values are obtained. The inverse of the coefficient of variation of the original variables is used as weight for obtaining the pattern of development. The findings are in the line with Narain et. al, 2000, 2002, 2003, 2004 is applied to construct the composite index of development for different state. The composite indices work out separately for agricultural, livestock, socio-economic and infrastructural fields. The value of the composite index lies between 0 and 1 . A value close to 0 indicates high level of development and a value near to one indicates poor 
level of development, the association between the levels of development of different sectors of economy. For low states, improvements needed in various indicators are also presented.

Knowledge of the level of the development will help in identifying where a given state stands in relation to other. The study also throws light on the relationships of socio-economic development with the agricultural development, livestock development and infrastructural facilities. To have definite conclusion and genuine remedies how ever more parameter and data are essential.

To examine the relationship among development of agricultural, livestock, socio-economic, infrastructure sectors and total literacy, a pair wise correlations have been worked out.

\section{Results and Discussions}

The composite indices of development have been worked out separately for agricultural sector, livestock sector, socio-economic sector and infrastructure sector for different state and given in Table 1 . The sectors have also been ranked on the basis of level of development. It may be seen from the table that in case of agriculture development, the state Assam is ranked first and the state Mizoram is ranked last. The composite indices of development vary from 0.21 to 0.74 incase of agriculture facilities. While in case of livestock development Mizoram state is found to be on the first position and Tripura state is ranked last. The composite index varies from 0.71 to 0.95 . In socio-economic development, the state of Assam is ranked first and the state Meghalaya is ranked last. The composite indices of development vary from 0.44 to 0.89 . Whereas, in the infrastructure development, the state Assam is ranked first and the state Mizoram is ranked last. The composite indices of development vary from 0.22 to 0.73 . (Sharma et al., 2008).

Table 1. Composite index of development

\begin{tabular}{llllllllll}
\hline S. N. & States & \multicolumn{2}{c}{ Agriculture } & \multicolumn{2}{c}{ Livestock } & \multicolumn{2}{c}{ Socio-econo. } & \multicolumn{2}{c}{ Infrastru } \\
& & CI & Rank & CI & Rank & CI & Rank & CI & Rank \\
\hline 1. & A. Pradesh & 0.68 & 6 & 0.89 & 6 & 0.84 & 6 & 0.53 & 2 \\
2. & Assam & 0.21 & 1 & 0.74 & 2 & 0.44 & 1 & 0.22 & 1 \\
3. & Manipur & 0.56 & 3 & 0.83 & 3 & 0.50 & 2 & 0.59 & 3 \\
4. & Meghalaya & 0.57 & 4 & 0.87 & 5 & 0.89 & 7 & 0.69 & 6 \\
5. & Mizoram & 0.74 & 7 & 0.71 & 1 & 0.72 & 4 & 0.73 & 7 \\
6. & Nagaland & 0.67 & 5 & 0.86 & 4 & 0.76 & 5 & 0.64 & 5 \\
7. & Tripura & 0.51 & 2 & 0.95 & 7 & 0.58 & 3 & 0.61 & 4 \\
\hline
\end{tabular}

\subsection{Different Stages of Development}

For relatives comparisons among the states with regard to the level of development, it appears appropriate to assume that the states having the composite indices less than or equal to Mean - SD are highly developed, whereas the state having the composite indices greater than or equal to (Mean $+\mathrm{SD}$ ) are low developed. States with composite index lying between (Mean - SD) and Mean are medium level developed and the state having the composite index between lying (Mean) and (Mean + SD) are at developing state. On the basis of this classification, states are put in four categories of development, high, medium, low and developing. Table 2 present the classification of states lying indifferent levels of development along with percentage area and population and present observation is based on standard conversion used in such derivation.

In case of agriculture development, the state Assam is found to be better developed as compared to other north eastern states. This better developed state occupies 30.75 per cent area and 69.20 per cent population of the north east regions covered under the study. The state Tripura is middle level developed covering 4.11 per cent area and 8.29 per cent population. The states Manipur, Meghalaya, Nagaland and Arunachal Pradesh are in the developing stage. These states covered 56.86 per cent area and 20.20 per cent population. The state Mizoram is observed to be in the low developed category. This state covers 8.26 per cent area and 2.32 per cent population; these findings are in the line with Narain et al., 2000 and Sharma et al., 2008. 
Table 2. Area and production in different levels of development

\begin{tabular}{lccl}
\hline A. AGRICULTURE & & \\
\hline Level of Development & Name of States & Area \% & Population \% \\
\hline High & Assam & 30.749 & 69.199 \\
Middle & Tripura & 4.111 & 8.289 \\
Developing & Manipur, Meghalaya, & 56.875 & 20.196 \\
& Nagaland \& Arunachal Pradesh & & \\
Low & Mizoram & 8.264 & 2.315 \\
\hline
\end{tabular}

B. LIVESTOCK

\begin{tabular}{lccl}
\hline Level of Development & Name of States & Area \% & Population \% \\
\hline High & Mizoram \& Assam & 39.014 & 71.514 \\
Middle & Manipur & 8.752 & 6.205 \\
Developing & Nagaland, Meghalaya, & 48.122 & 13.991 \\
& \& Arunachal Pradesh & & \\
Low & Tripura & 4.111 & 8.289 \\
\hline
\end{tabular}

\section{SOCIO-ECONOMIC}

\begin{tabular}{lccl}
\hline Level of Development & Name of States & Area \% & Population \% \\
\hline High & Assam \& Manipur & 39.503 & 75.405 \\
Middle & Tripura & 4.111 & 8.289 \\
Developing & Mizoram, Nagaland & 47.593 & 10.315 \\
\multicolumn{2}{l}{ \&ow } & Arunachal Pradesh & \\
\hline
\end{tabular}

\section{INFRASTRUCTURE}

\begin{tabular}{lccl}
\hline Level of Development & Name of States & Area \% & Population \% \\
\hline High & Assam & 30.749 & 69.199 \\
Middle & Arunachal Pradesh & 32.829 & 2.834 \\
Developing & Manipur, Tripura, Nagaland, & 36.420 & 27.966 \\
& Meghalaya \& Mizoram & & \\
Low & - & - & - \\
\hline
\end{tabular}

In case of livestock development, the states of Mizoram and Assam were found to be better developed as compared to other north eastern states. This better developed state occupies 39.01 per cent area and 71.51 per cent population of the regions covered under the study. The state Manipur is middle level developed covering 8.75 per cent area and 6.21 per cent population. The states of Nagaland, Meghalaya and Arunachal Pradesh are in the developing stage. These states covered 48.12 per cent area and 13.99 per cent population. The state Tripura is observed to be in the low developed category. This state covers 4.11 per cent area and 8.29 per cent populations, these findings are in the line with Narain et al., 2003 and Sharma et al., 2008.

Socio-economic development, the states Assam and Manipur are found to be better developed as compared to the rest of the north east states, these better developed states occupies 39.01 per cent area and 75.51 per cent population of the region. The state Tripura is middle level developed covering 4.11 per cent area and 8.29 per cent population. The states Mizoram, Nagaland and Arunachal Pradesh are in the developing stage. These states cover 47.59 per cent area and 10.32 per cent population. The state Meghalaya is observed to be in the low developed category. This state covers 8.79 per cent area and 5.99 per cent populations, these findings are in the line with Narain et al., 2004 and Sharma et al., 2008. 
Infrastructure facilities include medical, banking and overall economic enterprises available to the people in north east regions. The position of various states regarding the availability and use of the above facilities for the people is assessed by the composite index. It may be seen from the table that the state Assam is found to be better developed as compared to the rest of the north east states. This better developed state occupies 30.75 per cent area and 69.20 per cent population of the region. The state Arunachal Pradesh is middle level developed covering 32.83 per cent area and 2.83 per cent population. The states Manipur, Tripura, Nagaland, Meghalaya and Mizoram are in the developing stage. These states cover 36.42 per cent area and 27.97 per cent population. No state was observed to be in the low developed category under the infrastructure facilities, these findings are in the line with Narain et al, 2000 and Sharma et al., 2008.

\subsection{Inter-relationships among Different Sectors}

Table 3 reveals that for examine the relationship among development of agricultural, livestock, socio-economic, infrastructure sectors and total literacy, a pair wise correlations have been worked out.

Table 3. Pair wise correlation coefficient

\begin{tabular}{cll}
\hline S.No. & Pair of Sectors & Correlation Coefficient \\
\hline 1. & Agriculture and Livestock & 0.375 \\
2. & Agriculture and Socio-economic & 2.187 \\
3. & Agriculture and Infrastructure & $3.850 * *$ \\
4. & Agriculture and Total literacy & 0.557 \\
5. & Livestock and Socio-economic & 0.680 \\
6. & Livestock and Infrastructure & 0.580 \\
7. & Livestock and Infrastructure & -0.001 \\
8. & Socio-economic and Infrastructure & 1.748 \\
9. & Socio-economic and Total literacy & -0.690 \\
10. & Infrastructure and Literacy & 1.012 \\
\hline
\end{tabular}

** Significant at 1 per cent level

The correlation coefficient between the developments in agriculture and infrastructure sectors is found to be significantly at 0.01 probability level. However, the correlation coefficient between the development in agriculture and socio-economic facilities is not significant. The correlation coefficient between the development in infrastructural facilities and socio-economic sectors is also not significant. Infrastructural facilities in respect of banking, medical and other economic enterprises are also not found to be associated with the agricultural development. Literacy rate is also not associated with the agricultural, infrastructure and socio-economics development, these findings are in the line with Narain et al., 2004 and Sharma et al., 2008.

\subsection{Potential Targets for Low Developed States}

Table 4 reveals that the development among the north eastern states, it is important to examine the nature of improvement required in different indicators of low developed states for enhancing the level of development. This information is useful for readjusting the resources in reducing inequalities in levels of disparities in development among different states. It would also provided avenues to bring about uniform regional development in north east states. Potential targets of various development indicators for the low developed states have been determine by taking the best value among the states. (Narain et al., 2004) table also shows that the value of various important developmental indicators along with the potential targets. The following states were found low developed in agricultural, socio-economic sectors and in infrastructure facilities, these findings are in the line with Sharma et al., 2008. 
Table 4. Potential targets of low developed states

\begin{tabular}{llllc}
\hline \multicolumn{1}{c}{ Development Indicators } & Mizoram & Tripura & Meghalaya & Pot. target \\
\hline 1. Productivity of total cereals & 13.22 & 16.39 & 8.80 & 18.66 \\
2. Productivity of pulses & 17.12 & 18.95 & 10.03 & 23.50 \\
3. Productivity of oilseeds & 08.65 & 12.09 & 10.15 & 15.15 \\
4. Fish Productivity & 3.31 & 9.52 & 2.76 & 9.52 \\
5. Per capita cereal production & 0.13 & 0.16 & 0.12 & 0.37 \\
6. Productivity of commercial crops & 14.93 & 23.03 & 18.03 & 43.03 \\
7. No. of farms & 2 & 5 & 6 & 18 \\
8. Percentage net area irrigated & 5.17 & 13.67 & 13.58 & 24.20 \\
9. Percentage to total of Industries & 0.56 & 1.12 & 1.44 & 72.48 \\
10. All India Radio Station & 3 & 3 & 6 & 11 \\
11. No. of banks/ (in lakh population) & 4.94 & 1.03 & 3.73 & 8.11 \\
12. Per capita income (as $9^{\text {th }}$-FYP) & 18158.30 & 10894.91 & 10844.95 & 32720.96 \\
13. CD ratio of bank & 30.39 & 26.05 & 22.03 & 30.39 \\
14. Decadal growth rate & 29.18 & 15.74 & 29.94 & 64.41 \\
15. Total literacy & 74.44 & 63.81 & 50.75 & 74.44 \\
16. Birth rate & 25.75 & 26.55 & 45.86 & 45.86 \\
17. Death rate & 5.73 & 2.54 & 3.01 & 8.80 \\
18. Infant mortality rate & 1.41 & 1.34 & 1.98 & 1.98 \\
\hline
\end{tabular}

It is clear from the table that the values of such developmental indicators are very low as compared to the potential targets. In case of those indicators which are related to agriculture development like productivity of total cereals, pulses, oil seeds, farms, net irrigated area and per capita cereal production are very low in comparison to the corresponding potential targets.

\subsection{Mizoram}

Mizoram state peoples are chiefly practice jhum cultivation with low productivity of food grain crops, so it needs to development the agricultural as well as the socio-economic sectors including the forest products. Communication including road transport is not very satisfactory, which may be improved to enhance the production for ensuring per capita food production efficiency.

\subsection{Tripura}

Tripura state peoples are chiefly practice terraced cultivation encourage by the state government. Where as, on the other hand this state is low developed in infrastructure including education field, so welfare developmental programs may enhanced the required development.

\subsection{Meghalaya}

Meghalaya state peoples are mainly practicing jhum cultivation along with the terraced cultivation in some of the areas, due to encourage by the state government as well as by non-government organization (NGO). Even this state is low developed in agriculture and infrastructure, so welfare developmental programs may enhanced for the required development these findings are in the line with Narain et al., 2000 and Sharma et al., 2008.

\section{Conclusion \& Recommendation}

The broad conclusions emerging from the study are as follows:

Wide disparities in the level of development have been observed between different states of the north eastern region.

In Agriculture field, the Assam state is found to be better developed, followed by Tripura state at middle level developed, while Manipur, Meghalaya, Nagaland and Arunachal Pradesh are at the developing stage, while the 
Mizoram state is at low developed. While in the livestock sector Mizoram and Assam states was found to be better developed, Manipur state is at middle level developed, Nagaland, Meghalaya and Arunachal Pradesh states were at the developing stage, while the Tripura state is at low developed.

With respect to overall socio-economic development, Assam and Manipur states was found to be highly developed. Tripura state is at middle level developed. The Mizoram, Nagaland and Arunachal Pradesh states were at the developing stages even these states are making fast improvement in their level of development. The Meghalaya is found at low developed, this State requires care in implementation of developmental programs urgently.

Whereas the infrastructure development is high in Assam state, followed by Arunachal state at middle range. The Manipur, Tripura, Nagaland, Meghalaya and Mizoram states were at the developing stages even these states are making fast improvement in their level of development. Agriculture development is highly associated with Infra structure development.

\section{References}

Anonymous. (2006). Staistical Hand Book of Nagaland, Directorate of Economics and Statistics, Nagaland, Kohima.

Anonymous. (2008). Retrieved September 12, 2009 from http://indiabudget.nic.in

Anonymous. (2010). Retrieved October 10, 2010 from http://www.nedfi.databank

Narain, P., Sharma, S. D., Rai, S. C., \& Bhatia, V. K. (2000). Regional disparities in socio- economic development in Tamilnadu. J. Indian Society of Agricultural Statistics, 53, 35-46.

Narain, P., Sharma, S. D., Rai, S. C., \& Bhatia, V. K. (2000). Regional dimension of disparities in crop productivity in Uttar Pradesh. J. Indian Society of Agricultural Statistics, 54, 62-79.

Narain, P., Sharma, S. D., Rai, S. C., \& Bhatia, V. K. (2002). Dimensions of regional disparities in socio-economic development in Madhya Pradesh. Journal Indian Society of Agricultural Statistics, 55, 88-107.

Narain, P., Sharma, S. D., Rai, S. C., \& Bhatia, V. K. (2003). Evaluation of economic development at micro level in Karnataka. Journal Indian Society of Agricultural Statistics, 56, 52-63.

Narain, P., Sharma, S. D., Rai, S. C., \& Bhatia, V. K. (2004). Estimation of socio-economic development in Hilly states. Journal Indian Society of Agricultural Statistics, 58, 126-135.

Sharma, A., Dhakre, S. D., \& Sharma, R. (2008). Inter-District Disparities in Socio-Economic Development in Nagaland. Productivity, 49(2-3), 196-200. 